\title{
INTRODUCING VEGETABLE OILS IN A PREPARATION OF KETOCONAZOLE LIPOSOMES USING A THIN-FILM HYDRATION METHOD
}

\author{
OLGA POPOVSKA $^{1 *}$, ZORAN KAVRAKOVSKI $^{2}$, VESNA RAFAJLOVSKA $^{1}$ \\ ${ }^{I}$ Ss. Cyril and Methodius University in Skopje, Faculty of Technology and Metallurgy, Rudjer Boskovic 16, 1000 Skopje, \\ Republic of Macedonia \\ ${ }^{2}$ Ss. Cyril and Methodius University in Skopje, Faculty of Pharmacy, Majka Tereza 47, 1000 Skopje, Republic of Macedonia
}

*corresponding author: olga_popovska@yahoo.com

Manuscript received: December 2017

\begin{abstract}
Multilamellar ketoconazole liposome vesicles (MLV) were prepared using a thin-film hydration method. Sunflower and olive oil were introduced as solvents in a preparation of ketoconazole liposomes. The liposomes were evaluated by determination of morphological characteristics, encapsulation efficiency of ketoconazole and $\zeta$-potential. The highest encapsulation efficiency was found to be $91.21 \%$ in the ratio of ketoconazole, cholesterol, and L- $\alpha$-phosphatidylcholine 3.33:1:3.33 w/w/w.
\end{abstract}

\section{Rezumat}

Veziculele multilamelare de lipozomi cu ketoconazol (MLV) au fost preparate utilizând o metodă de hidratare sub formă de film subțire. Uleiurile de floarea-soarelui și măsline au fost utilizate ca solvenți într-un preparat lipozomal cu ketoconazol. Lipozomii au fost evaluați prin determinarea caracteristicilor morfologice, a eficienței de încapsulare a ketoconazolului și a potențialului $\zeta$. Cea mai mare eficiență a încapsulării a fost de $91,21 \%$, în cazul folosirii raportului dintre ketoconazol, colesterol și L- $\alpha$-fosfatidilcolină de 3,33:1:3,33 m/m/m.

Keywords: ketoconazole, lecithin, liposome, vegetable oil

\section{Introduction}

The liposomes are appropriate for drug delivery via many routes, due to their amphipathic character: oral, nasal, topical, ocular, and muscular, improving in vitro and in vivo activity $[1,6]$. The application of liposomes increases due to properties as non-toxicity, flexibility, biodegradation, as well as improvement of encapsulated drugs stability in vesicles [3, 4]. The main precaution in the liposomal application involves instability related to hydrolysis, reactions of peroxidation, aggregation, and drug permeability. To overcome this issue, cholesterol, lipids with short chains, saturated bonds or oil from grape seed, olive, and almond are introduced [7].

Ketoconazole is an imidazole antimycotic lipophilic drug [8] mainly used in the treatment of supercritical and systemic fungal infections $[8,10]$. In the literature, ketoconazole liposomes were prepared using the thinfilm hydration [8] and the chloroform injection method [10]. The reported data in the literature are related to preparation of ketoconazole multilamellar liposome vesicles (MLV) using soya lecithin phospholipid and dichloromethane [8].

The aim of this study was to prepare ketoconazole liposomes using the thin-film hydration method. The vegetable oil was introduced to overcome the problems with residues of halogenated solvents in the obtained liposomes, as well as the use of phospholipid source. The obtained ketoconazole liposomes were evaluated for morphological appearance, encapsulation efficiency, and potential changes on the vesicle surface.

\section{Materials and Methods}

Standard ketoconazole was obtained from the Pharmaceutical Company, Replek Farm DOOEL (Skopje, Republic of Macedonia) as a gift sample. Analytical grade methanol, ethyl acetate, and chloroform were supplied from Merck (Germany). Cholesterol was supplied from Calbiochem (Japan), while L- $\alpha$ phosphatidylcholine (egg yolk) from Sigma (Germany). The vegetable sunflower and olive oils were purchased from the local market in the Republic of Macedonia. The $\zeta$-potential and the electrical conductivity were measured on a zeta potentiometer Zeta meter 4.0 (USA). The microscopic analyses were performed on an optical microscope Konus, type M-100-FL (Italy) with magnification of 40x. A digital camera Sony, Cybershot W, type DSCW830V.CE3 and lens ZEISS VarioTessar 8x (China) were used in the photomicrography. Preparation of the ketoconazole liposomes

The liposomes were evaluated in terms of the influence of solvents, the ratio of ketoconazole, cholesterol, 
FARMACIA, 2019, Vol. 67, 3

phospholipid, hydration media (water or $0.9 \% \mathrm{NaCl}$ ), and preparative conditions such as number of centrifugal rotations. The selected temperature of $80^{\circ} \mathrm{C}$ for hydration was higher than transition temperatures of phospholipid $\left(65^{\circ} \mathrm{C}\right)$ and the lipid acids $\left(23-67^{\circ} \mathrm{C}\right)$ in sunflower and olive oil $[2,5]$. Ketoconazole lipid mixture was stirred at $65^{\circ} \mathrm{C}$ due to the destructive influence of higher temperatures on the liposomal structure [2, 6]. In this study, less irritable lecithin from egg yolk was included in the formulation of liposomes instead of soya lecithin that was used by Patel et al. [8] and Sahasrabuddhe et al. [10]. Ketoconazole, cholesterol, and lecithin were weighed and transferred to a round-bottom flask. Solvents were used in quantity of $5 \mathrm{~mL}$. The mixture was homogenized on the magnetic stirrer $(1000 \mathrm{rpm})$ at $40^{\circ} \mathrm{C}, 10 \mathrm{~min}$. In the hydration step, the hydration mean $(5 \mathrm{~mL})$ was added at $80^{\circ} \mathrm{C}$. The liposomes were obtained by stirring the ketoconazole lipid mixture on the rotary evaporator at $65^{\circ} \mathrm{C}$ for $1 \mathrm{~h}$ with a constant rotational speed $(90 \mathrm{rpm})$. A thin film was obtained on the inner surface of the flask, followed by cooling at $25^{\circ} \mathrm{C}$ and left at $4{ }^{\circ} \mathrm{C}$ for $24 \mathrm{~h}$ to achieve full hydration. The unentrapped ketoconazole was removed from the liposomal dispersion by centrifugation at $4000 \mathrm{rpm}$ or $5000 \mathrm{rpm}$ for $15 \mathrm{~min}$. A liposomal part was formed between the water and oil phase when oil was used as solvent. In case of methanol, due to its removal during the evaporation process, liposomal upper and aqueous lower phase were separated.

Evaluation of ketoconazole liposomes

The ketoconazole liposomes obtained were evaluated for morphological appearance, encapsulation efficiency, and potential changes on the vesicle surface.

Microscopic analysis of the ketoconazole liposomes The morphology of ketoconazole liposomes was observed under the optical microscope with magnification of $40 \mathrm{x}$.

Encapsulation efficiency of ketoconazole in liposomes Liposomal formulation of ketoconazole was dissolved in methanol $(5 \mathrm{~mL})$. The entrapped ketoconazole quantity in liposomes was determined at $296 \mathrm{~nm}$ with the UV spectrophotometric method proposed by Popovska et al. [9]. The spectroscopic absorption maxima of egg-yolk phospholipid $\left(\lambda_{\max }=240 \mathrm{~nm}\right)$ and cholesterol $\left(\lambda_{\max }=235 \mathrm{~nm}\right)$ showed no interference in quantity analysis of ketoconazole.

The $\zeta$-potential and the electrical conductivity (EC) Prior to measurement of $\zeta$-potential and the electrical conductivity at $22^{\circ} \mathrm{C}$ and $300 \mathrm{~V}$, the ketoconazole liposomes $(500 \mu \mathrm{L})$ were diluted with distilled water in $50 \mathrm{~mL}$ volumetric flask.

Stability study

The ketoconazole liposomes were evaluated for morphological appearance and entrapped efficiency of ketoconazole during one-month storage at $4^{\circ} \mathrm{C}$ and $25^{\circ} \mathrm{C}$.

\section{Results and Discussion}

Table I presents the values of $\zeta$-potential and EC of the ketoconazole liposomes prepared during the study of the influence on the solvent type.

Table I

Influence of the solvent type on the potential surface ( $\zeta$-potential) and electrical conductivity (EC) on ketoconazole liposomes

\begin{tabular}{|c|c|c|c|c|c|c|}
\hline Sample & $\begin{array}{c}\text { KT } \\
(\mathrm{mg})\end{array}$ & $\begin{array}{l}\text { SO } \\
(\mathrm{mg})\end{array}$ & $\begin{array}{c}\text { CL } \\
(\mathrm{mg})\end{array}$ & $\begin{array}{c}\text { Solvent } \\
\left(\mathrm{cm}^{3}\right)\end{array}$ & $\zeta$-potential & $\begin{array}{c}\text { EC } \\
(\mu \mathrm{S} / \mathbf{c m})\end{array}$ \\
\hline a & 20 & 517 & 20 & $10^{\mathrm{a}}$ & -28.36 & 9.35 \\
\hline b & 20 & 501 & 20 & $10^{\mathrm{a}}$ & -24.06 & 9.02 \\
\hline c & 20 & 513 & 20 & $10^{\mathrm{b}}$ & -18.03 & 9.75 \\
\hline d & 21.7 & 327 & 21.1 & $10^{\mathrm{c}}$ & -23.71 & 13.45 \\
\hline e & 20 & 200 & 20 & $10^{\mathrm{c}}$ & -19.92 & 14.53 \\
\hline f & 20 & 516.3 & 20 & $5^{\mathrm{a}}$ & -30.95 & 8.95 \\
\hline g & 20 & 501 & 20 & $3.5^{\mathrm{a}}+3.5^{\mathrm{c}}$ & -23.01 & 12.05 \\
\hline h & 1 & 513.7 & 20 & $10^{\mathrm{c}}$ & -14.26 & 18.00 \\
\hline
\end{tabular}

KT - ketoconazole; SO - sunflower oil; CL - cholesterol; ${ }^{\mathrm{a} C h l o r o f o r m},{ }^{\mathrm{b}}$ Ethyl acetate; ${ }^{\mathrm{c}}$ Methanol

The values for the $\zeta$-potential were $-24.06 \mathrm{mV}$ and $-23.71 \mathrm{mV}$ using ethyl acetate and methanol (Table I, sample c, d). Even the highest value of the $\zeta$ potential $(-30.95 \mathrm{mV})$ was measured for the liposomes prepared using chloroform (Table I, sample a), in further research methanol was used, according to the characteristics of the solvents and their impact on human and environment health [11]. An increased quantity of sunflower oil that was used in the formulations as a source of phospholipid positively influenced on the $\zeta$-potential values (Table I, sample $\mathrm{a}, \mathrm{b}$ and $\mathrm{d}, \mathrm{e})$. The "empty liposome" showed the lowest value for the $\zeta$-potential $(-14.26 \mathrm{mV}$, Table I, sample $h$ ), taking into consideration the absence of a substance for the electricity transmission [6]. The ketoconazole liposomes obtained were "milky white" coloured vesicles with expressed radiance for vegetable oil formulations, and pale hue for the liposomes when methanol was used. The encapsulation efficiency for ketoconazole liposomes is presented in Table II. 
The encapsulation efficiency (EE) increased from $65.11 \%$ to $85.82 \%$ by changing the rotational speed from 4000 to $5000 \mathrm{rpm}$. A decreasing value of $50.84 \%$ for EE was determined at $9000 \mathrm{rpm}$ compared to $5000 \mathrm{rpm}$. The separation of ketoconazole in the supernatant at higher velocities resulted in EE values decrease, also confirmed in the literature [1, 2]. Ketoconazole amount increase from 100 to $1100 \mathrm{mg}$ resulted in lower EE values about $11 \%$ and $21 \%$, using sunflower and olive oil mixture, and sunflower oil, respectively. Costa and Moraes [5] determined that encapsulation efficiency decreased due to the deficient of active areas at smaller phospholipid quantity. The ketoconazole EE was $74.11 \%$ using methanol as solvent during the liposome preparation. The mixture of sunflower and olive oil that was used in formulation (Table II, sample h) resulted in $17.1 \%$ higher value for the entrapped ketoconazole in liposomes compared to methanol (Table II, sample g). The ketoconazole EE was $91.21 \%$ and $82.21 \%$ with water and $0.9 \% \mathrm{NaCl}$, respectively. Aukunuru et al. [3] confirmed the EE value decrease due to the incomplete dissolution of the ionic substance in the lipid. The highest value for the encapsulation efficiency $(93 \%)$ was obtained for the formulation without lecithin. The possibility of emulsion formation was associated with the undefined strict borders between the layers [6]. The insignificant differences in the $\zeta$ potential values was determined when vegetable oils $(-27.43 \mathrm{mV})$ and methanol $(-27.54 \mathrm{mV})$ at $5000 \mathrm{rpm}$ were used as solvents.

Table II

Influence of the solvent quantity, type of hydration medium (HM), and rotational speed (RS) on the encapsulation efficiency (EE) of liposomes

\begin{tabular}{|c|c|c|c|c|c|c|c|c|}
\hline Sample & $\begin{array}{c}\mathbf{K T} \\
(\mathbf{m g})\end{array}$ & $\begin{array}{c}\mathbf{C L} \\
\mathbf{( m g )}\end{array}$ & $\begin{array}{c}\mathbf{F L} \\
(\mathbf{m g})\end{array}$ & $\begin{array}{c}\mathbf{O L} \\
(\mathbf{m L})\end{array}$ & $\begin{array}{c}\mathbf{M E} \\
\mathbf{( m L )}\end{array}$ & $\begin{array}{c}\mathbf{H M} \\
(\mathbf{m L})\end{array}$ & $\begin{array}{c}\mathbf{R S} \\
(\mathbf{R P M})\end{array}$ & $\begin{array}{c}\mathbf{E E}^{\mathbf{1}} \pm \mathbf{S D} \\
\mathbf{( \% )}\end{array}$ \\
\hline $\mathbf{a}$ & 100 & 30 & 100 & $9.9^{\mathrm{a}}$ & 5 & water & 4000 & $65.11 \pm 0.18$ \\
\hline $\mathbf{b}$ & 100 & 30 & 100 & $9.9^{\mathrm{a}}$ & 5 & water & 5000 & $85.82 \pm 0.04$ \\
\hline $\mathbf{c}$ & 100 & 30 & 100 & $9.9^{\mathrm{a}}$ & 5 & water & 9000 & $43.63 \pm 0.85$ \\
\hline $\mathbf{d}$ & 100 & 30 & 100 & $9.1^{\mathrm{b}}$ & 5 & water & 5000 & $66.08 \pm 0.11$ \\
\hline $\mathbf{e}$ & 1100 & 30 & 100 & $9.9^{\mathrm{a}}$ & 5 & water & 5000 & $73.35 \pm 0.41$ \\
\hline $\mathbf{f}$ & 1100 & 30 & 100 & $9.1^{\mathrm{b}}$ & 5 & water & 5000 & $45.37 \pm 0.54$ \\
\hline $\mathbf{g}$ & 100 & 30 & 100 & - & 5 & water & 5000 & $74.11 \pm 0.63$ \\
\hline $\mathbf{h}$ & 100 & 30 & 100 & $5^{\mathrm{a}}$ & - & water & 5000 & $91.21 \pm 0.94$ \\
\hline $\mathbf{i}$ & 100 & 30 & 100 & $5^{\text {a }}$ & - & water & 4000 & $88.31 \pm 0.19$ \\
\hline $\mathbf{j}$ & 100 & 30 & 100 & $5^{\text {a }}$ & - & $0.9 \%$ NaCl & 5000 & $82.21 \pm 0.52$ \\
\hline $\mathbf{k}$ & 1.1 & 3 & - & $5^{\text {a }}$ & - & water & 5000 & $93.77 \pm 0.54$ \\
\hline
\end{tabular}

KT - ketoconazole; CL - cholesterol; FL - phospholipid; OL - oil; ME - methanol; ${ }^{a}$ Sunflower and olive oil (1:1 v/v); ${ }^{b}$ Sunflower oil; ${ }^{1}$ Mean value $(n=3) \pm$ standard deviation (SD)

The morphological appearance of the ketoconazole liposomes prepared with thin-film hydration method is presented in Figure 1.

The well identified spherical ketoconazole vesicles composed of many concentric phospholipid bilayers were in accordance with Patel et al. [8] and Sahasrabuddhe et al. [10]. The liposomes prepared with methanol as solvent showed a specific multilamellar spherical structure (Figure 1, sample g). The multilamellar well differentiated structure was noticed for the liposomes obtained at $5000 \mathrm{rpm}$ (Figure 1, sample $\mathrm{h}$ ) instead of the aggregated liposomes prepared at $4000 \mathrm{rpm}$ (Figure 1, sample i). A spherical form existed in formulations using $\mathrm{NaCl}$ (Figure 1, sample j). The liposomes without lecithin were characterized by non-spherical and multilamellar structure (Figure 1, sample j). Taking into account the ketoconazole encapsulation efficiency, as well as the microscopic appearance, the most satisfactory formulation was the one with oil and water at the rotational speed of $5000 \mathrm{rpm}$ (Table II, sample h).

The EE values determined for formulation $h$ (Table II) during stability evaluation during one month at temperatures of $4^{\circ} \mathrm{C}$ and $25^{\circ} \mathrm{C}$ are presented in Figure 2.

After one month of liposomes storage at $4^{\circ} \mathrm{C}$ and $25^{\circ} \mathrm{C}$, compared to the initial value at 0 days, the encapsulation efficiency decreased for $17.04 \%$ and $35.31 \%$, respectively. The higher storage temperature $\left(25^{\circ} \mathrm{C}\right)$ affected the significant decrease on the EE values, and caused structural changes in vesicles with the impact of aggregation and fusion that correlated with the findings confirmed by Chanda et al. [4]. No changes in morphology were recorded in ketoconazole liposomes after one-month storage at $4^{\circ} \mathrm{C}$. The introduction of vegetable oil is justified to overcome the issues with residues of the organic solvents in the obtained liposomes and also to serve as source of phospholipid with L- $\alpha$-phosphatidylcholine. 

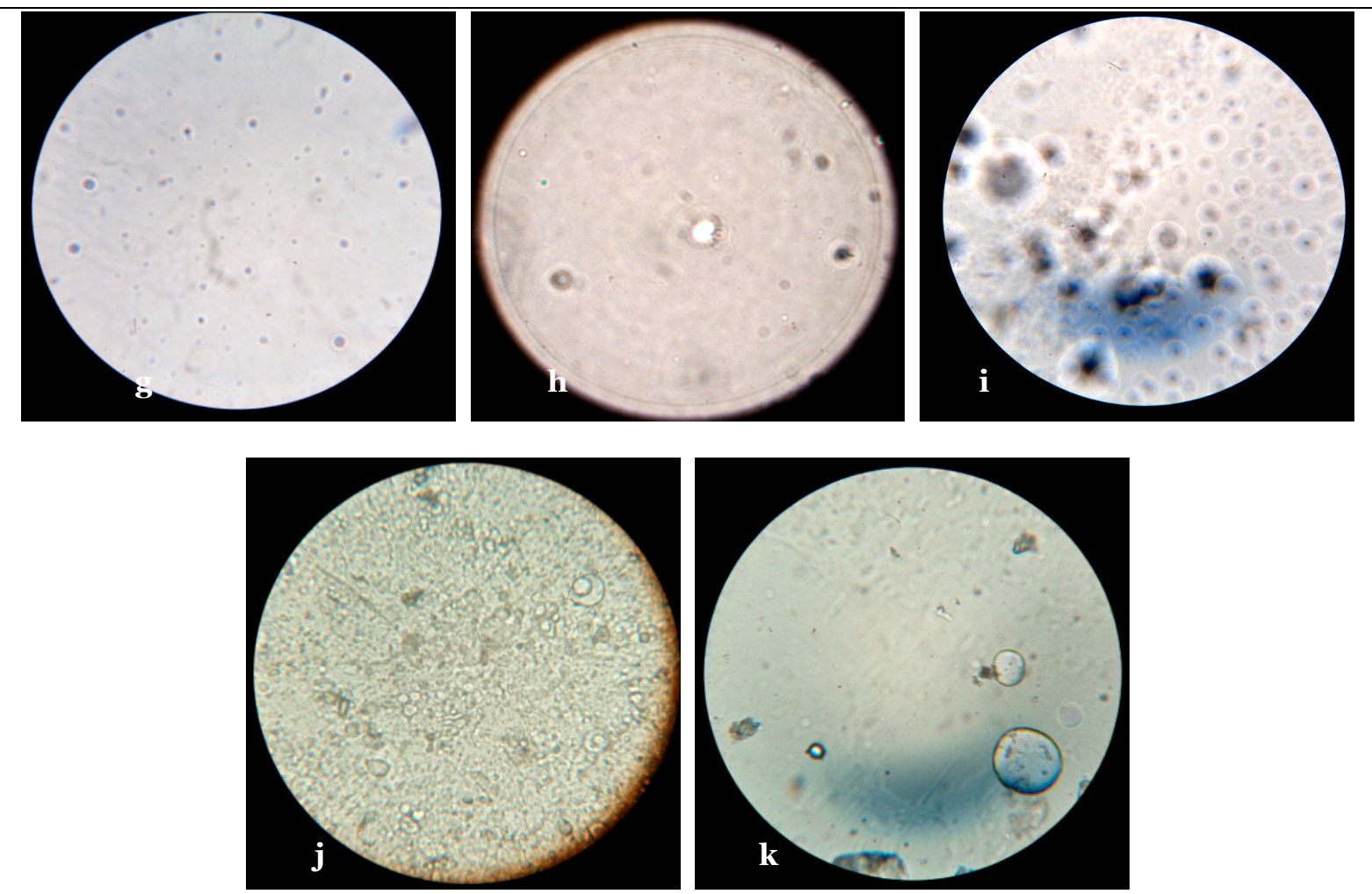

Figure 1.

Photomicrographs of the ketoconazole liposomes ( $\mathrm{g}-\mathrm{k}$ correspond to the samples given in Table II)

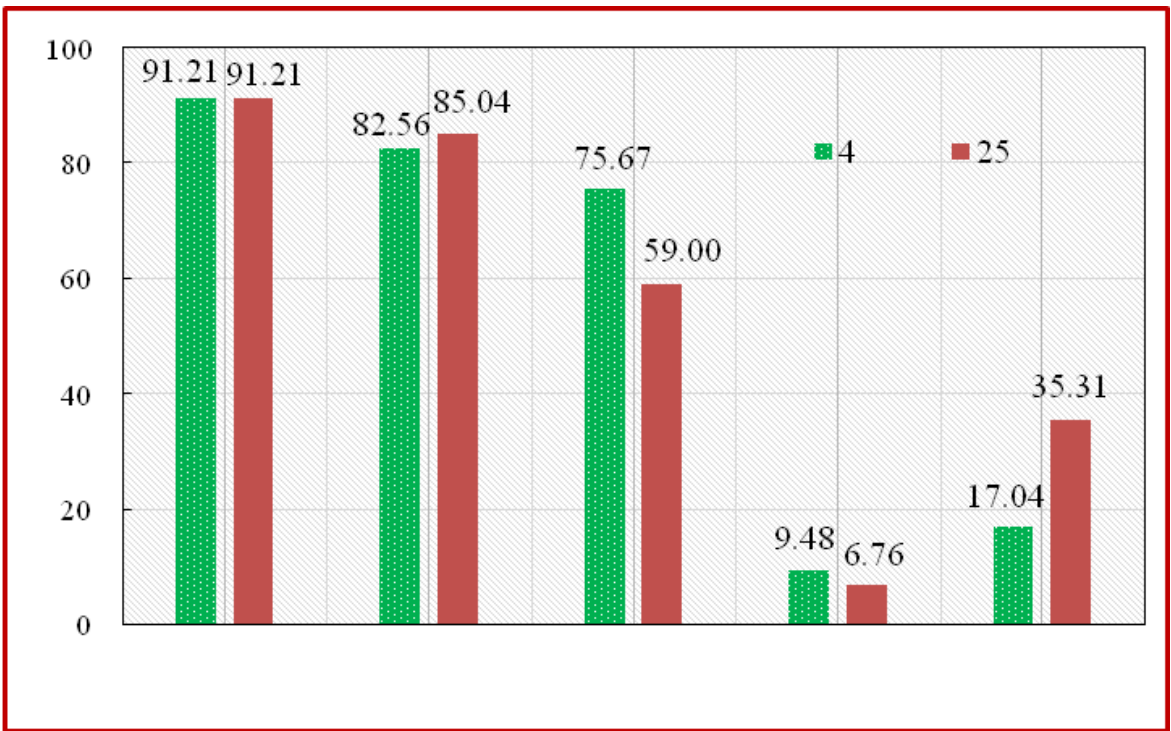

Figure 2.

Stability test of liposomes (Table II, sample h) at $4^{\circ} \mathrm{C}$ and $25^{\circ}$

\section{Conclusions}

The use of the commercial available vegetable oil is a new, safe, cost-effective, and eco-friendly approach in the ketoconazole liposomal preparation using the thin-film hydration method. Taking into account the high values of the encapsulated efficiency and the $\zeta$-potential, as well as the satisfactory structural characteristics and stability of the prepared ketoconazole liposomes, the introduction of the vegetable oils in liposomal technology instead of the halogenated solvents and high cost phospholipids is of high importance in future research in delivery systems and therapies.

\section{References}

1. Achim M, Precup C, Gonganău-Niţu D, Barbu-Tudoran L, Porfire AS, Scurtu R, Ciuce C, Thermosensitive liposomes containing doxorubicin. Preparation and in vitro evaluation. Farmacia, 2009; 57(6): 703-710. 
2. Andhale VA, Patil PR, Dhas AU, Chauhan PD, Desai SV, Liposome: an emerging tool in drug carrier system. IJPT, 2016; 8: 10982-11011.

3. Aukunuru J, Joginapally S, Gaddam N, Burra M, Bonepally CR, Preparation, characterization and evaluation of hepatoprotective activity of an intravenous liposomal formulation of bis-demethoxy curcumin analogue (BDMCA). Int J Drug Dev \& Res., 2009; 1: 37-46.

4. Chanda H, Das P, Chakraborty R, Ghosh A, Development and evaluation of liposomes of fluconazole. J Pharm Biomed Sci., 2011; 5: 1-9.

5. Da Costa CAM, Moraes ÂM, Encapsulation of 5fluorouracil in liposomes for topical administration. Acta Sci Technol., 2003; 25: 53-61.

6. Dua JS, Rana AC, Bhandari AK, Liposome: methods of preparation and applications. IJPSR, 2012; 3: 1420.

7. Gibis M, Rahn N, Weiss J, Physical and oxidative stability of uncoated and chitosan-coated liposomes containing grape seed extract. Pharmaceutics, 2013; 5: 421-433.

8. Patel RP, Patel H, Baria AH, Formulation and evaluation of liposomes of ketoconazole. IJDDT, 2009; 1: 16-23.

9. Popovska O, Kavrakovski Z, Rafajlovska V, Development and validation of UV spectroscopic method for determination of ketoconazole in pharmaceutical formulations. Int J Pharm., 2014; 4: 95-101.

10. Sahasrabuddhe SH, Bajpai N, Bais S, Ganesan S, Ketoconazole: liposomal drug delivery system-a boon for cosmetic industry. Int J Advan Pharm Sci., 2012; 3: 109-116.

11. WHO, Library Cataloguing-in-Publication Data. Chloroform. Concise international chemical assessment document, Wissenschaftliche Verlagsgesellschaft $\mathrm{mbH}$, Stuttgart, Germany., 2004; 58. 